\title{
Assessment of Quarantine Understanding and Adherence to Lockdown Measures During the COVID-19 Pandemic in Palestine: Community Experience and Evidence for Action
}

\section{OPEN ACCESS}

Edited by:

Roger Hewson,

Public Health England,

United Kingdom

Reviewed by:

Mohammed Alkhaldi,

McGill University, Canada

Giuseppe Battaglia,

University of Palermo, Italy

Mostafizur Rahman,

Jahangirnagar University, Bangladesh

*Correspondence:

Hamzeh Al Zabadi

halzabadi@gmail.com

tThese authors have contributed equally to this work

Specialty section: This article was submitted to Infectious Diseases - Surveillance,

Prevention and Treatment,

a section of the journal

Frontiers in Public Health

Received: 06 June 2020

Accepted: 08 February 2021

Published: 02 March 2021

Citation:

Al Zabadi H, Yaseen N, Alhroub T and Haj-Yahya M (2021) Assessment of

Quarantine Understanding and Adherence to Lockdown Measures

During the COVID-19 Pandemic in

Palestine: Community Experience and

Evidence for Action.

Front. Public Health 9:570242. doi: 10.3389/fpubh.2021.570242

\author{
Hamzeh Al Zabadi ${ }^{1 *}$, Noor Yaseen ${ }^{2 \dagger}$, Thair Alhroub ${ }^{2 \dagger}$ and Maryam Haj-Yahya ${ }^{2+}$ \\ ${ }^{1}$ Public Health Department, Faculty of Medicine and Health Sciences, An-Najah National University, Nablus, Palestine, \\ ${ }^{2}$ Medicine Department, Faculty of Medicine and Health Sciences, An-Najah National University, Nablus, Palestine
}

Background: Containment of the coronavirus pandemic relied extensively on the combination of early implementation of quarantine and massive behavioral changes to ensure effectiveness. Decision-makers need to constantly monitor the outbreak situation and the impact of the measures implemented. Yet little is known about the factors influencing adherence and understanding of lockdown measures among the Palestinian community. This study aimed to assess the impact and factors affecting these early public health interventions.

Materials and Methods: A cross-sectional web-based questionnaire was distributed throughout social media (Facebook and Instagram). We used a snowball recruiting technique to target Palestinian adult citizens during the coronavirus pandemic quarantine between 6 and 16 April 2020, which corresponded to almost the middle interval of the strict massive lockdown measures in Palestine that lasted from 22 March to 5 May 2020. Multivariate logistic regression models were developed for the outcome variables (staying home adherence, in-home precautions adherence, and quarantine understanding).

Results: Our questionnaire was completed by 2,819 participants. The mean (range) age was 29.47 (18-71) years. Of them, 1,144 (40.6\%), 1,261 (44.7\%), and 1,283 (45.5\%) reported low levels of staying home adherence, in-home precautions adherence, and quarantine understanding, respectively. Females, city residents, those with higher educational levels, and those informed by official government sources were associated significantly with higher levels of both staying home adherence and quarantine understanding. Adequate food supply was associated with a higher level of staying home adherence. Higher levels of in-home precautions adherence were noticed in the elderly and those with a high-risk group living at home. Higher monthly income was inversely associated with higher levels of in-home precautions adherence and lower levels of quarantine understanding $(P<0.05)$.

Conclusions: The socio-economic and financial status of the general population and coordination between the major information resources (official government), social media, 
and the press were the major factors affecting the community in regard to quarantine adherence. For maximum effectiveness and commitment levels amongst the people to decrease the spread of infection, policymakers need to address all those factors. In addition, clear communication between policymakers and the population is essential for reassuring the people and minimizing their fears regarding the unknown future.

Keywords: COVID-19, lockdown, Palestine, pandemic, perceptions, quarantine, adherence

\section{BACKGROUND}

On 11 March 2020, the WHO declared COVID-19 to be a pandemic (1). As the treatment was mainly symptomatic and supportive, protection, and prevention of infection transmission were the best choices worldwide (2). Quarantine announcements were asserted simultaneously almost all over the world. In Palestine, quarantine took place on 22 March 2020 as the first cases of COVID-19 were confirmed (3).

According to the Center for Disease Control and Prevention (CDC), quarantine was adopted as an obligatory means to separate and restrict the movement of people who had potentially been exposed to a contagious disease. People also had to follow appropriate infection control measures which included bans on large social gatherings, school closures, the ban of weddings, parties, and funerals, closures of entertainment venues, various restrictions on restaurant dining areas and gyms, such as increasing the distance between tables and gym machines and improving ventilation to prevent the virus droplet transmission. Adding to this, travel restrictions and social distancing measures were introduced during quarantine (4-7). These measures were implemented to limit disease spread, morbidities, mortalities, and decrease the burden on the health care system, as witnessed before in history with cholera, plague, and influenza (8).

The utility of quarantine is undetermined, and whether or not overusing it can be of any benefit lacks any scientific basis. However, one thing is certain according to a rapid review on how to improve adherence with quarantine: quarantine does not work if people do not adhere to it $(9,10)$.

Previous surveys on factors that affect adherence to quarantine in outbreaks were reviewed. Multiple factors were studied to assess their effect on the adherence to quarantine and protective health behaviors such as hand washing, avoiding crowds, and maintaining social distance between individuals. Some of these factors were of direct influence and reflected higher adherence actions, such as knowledge about the infectious disease outbreak and quarantine protocol, the perceived benefits of quarantine, the grasped risks of the disease, and the social norms that pressured others to comply with the quarantine. Other factors were of alternative effects, such as where people got their knowledge of quarantine protocols from, with no difference in adherence rates between those who sourced information from official vs. non-official sources. In addition, practical issues such as financial consequences or employees in insecure jobs who lacked leave entitlement would result in individuals being less likely to comply with social distance measures (11). Trust in the government's public health interventions, pre-existing positive appraisal of the health care system, and trust in the national response predicts more adherence to the quarantine $(8,9,12)$.

A study in Norway found that adherence to quarantine has been low, especially after the initial surge of infections faded nationwide, which suggests that people are influenced by the perceived infection risk or that the population experiences quarantine fatigue and a wish to return to normality (12).

Recent studies on the topic of the associated predictors with quarantine and health measure compliance showed that gender, age, geographic area, and employment status, as well as the person's fear for themselves and others to contract COVID-19, were significantly predictive (13).

There is very limited data that evaluates the possible predictors which could influence the general population's staying home adherence and the understanding of quarantine and lockdown measures during the COVID-19 pandemic in Palestine. This study is dedicated to providing a clear vision regarding the situation by expanding on the limited knowledge about the possible implicated factors in quarantine compliance. Overall, this could allow the decision-makers to constantly monitor and maintain the balance between the implementation of quarantine and public health measures.

\section{MATERIALS AND METHODS \\ Study Population, Sample, and Setting}

The target population comprised every Palestinian who lived in the West Bank, Gaza, or Jerusalem during coronavirus2 quarantine and who was equal to or more than 18 years old. We adopted a cross-sectional web-based survey design to assess the public's adherence to quarantine and infection control instructions during the lockdown of coronavirus- 2 pandemic by using an anonymous online questionnaire. Every person had a number that reflected their order by the time they finished the questionnaire. A snowball sampling technique was used and focused on recruiting any Palestinian who lived in Palestine during the pandemic. The online survey was disseminated on Facebook and Instagram to friends and local pages and they were encouraged to pass it on to others. A mandatory question was added on the first page of the questionnaire regarding current residency. Those who reported living outside Palestine were automatically excluded from the study. We were able to recruit 2,819 participants in this study who completely filled and returned the questionnaire, with an age range between 18 and 71 years old. 


\section{Questionnaire Development}

After reviewing related factors that affect adherence to quarantine in outbreaks $(9,14,15)$, we included additional questions related to the COVID-19 pandemic. The structured questionnaire consisted of questions that covered several areas: (1) informed consent, (2) demographic data, (3) knowledge and concerns about quarantine, and (4) compliance to precautionary measures against coronavirus inside and outside the home. The data collection tool was revised by two experts in the field. Then, a pilot study was performed on 56 volunteers of the author's Facebook friends and relatives and their friends (nine of them were older than 30) for feedback to identify ambiguities, questionnaire structure errors, difficult questions, and to record the time taken to complete the questionnaire. Then we took into consideration their notes and edited them as needed; after that, they reviewed the second version and accepted it.

\section{Procedure and Ethical Consideration}

As the Palestinian Government recommended the public to minimize face-to-face interaction and isolate themselves at home, the questionnaire was distributed electronically. Participants completed it in Arabic through an online survey. Expedited ethical approval was obtained from the Institutional Review Board (IRB) at An-Najah National University. Privacy was strictly protected during the procedure as we avoided any questions that could expose the identity of respondents. Information and the purpose of the study were posted on the first page of the questionnaire. All respondents provided electronic informed consent before starting the questionnaire. Data collection took place over 10 days (6-16 April 2020) which corresponded to almost the middle interval of the massive quarantine in Palestine where restriction measures were at their highest (22 March to 5 May 2020).

\section{Statistical Analysis}

Quarantine understanding outcome reflects the knowledge and information the person has about the pandemic and quarantine regardless of the source. It was initially evaluated through five statements: (1) quarantine is needed where I live, (2) not committing to quarantine will raise the number of cases, (3) measures taken by the government are necessary, (4) quarantine should not only be limited to infected people and those who are in contact with them, and (5) hygiene measures in the house are part of quarantine. A 5-point Likert scale [strongly agree (4), agree (3), neutral (2), disagree (1), and totally disagree (0)] was used to respond to each statement. By summing the points of each statement, a scale from 0 to 20 was created for each respondent. We then used the median as a cutoff point to categorize this outcome into a low level (0-17) and a high level (18-20).

Staying home adherence outcome reflects the compliance of the individual to the main instruction given by the government: "Do not leave the house if it is not necessary." It was initially evaluated through five statements: (1) going grocery shopping or to the bakery, (2) going out meeting friends or family, (3) going out to spend time and have fun, (4) attending social events, and (5) going to the pharmacy. The answer to each statement is composed of [never going out (3), some days (2), more than half of days (1), and every day (0)].
In-home precautions adherence outcome reflects the compliance to infection control measures while staying inside the home to decrease the spread of infection between family members. It was initially evaluated through five statements: (1) washing your hands for 20 seconds or more, (2) decrease the time of interaction with other family members, (3) washing hands after returning from outside, (4) sneezing appropriately according to guidelines (using a tissue or using elbow), and (5) not sharing towels and items between family members. The answer to each statement is composed of [never do them (0), do them sometimes (1), do them most of the time (2), and always do them (3)].

For these last two outcomes separately, we summed up the points of each statement. A scale from 0 to 15 was created for each respondent. Then the median was used as the cutoff point to categorize staying home adherence outcome to a low level (0-12) and a high level (13-15) while categorizing in-home precautions adherence outcome to a low level (0-10) and a high level (11-15).

The 27th version of IBM SPSS (IBM SPSS Statistics for Windows, Version 27.0. Armonk, NY: IBM Corp) was used for data coding, entry, and analysis. All parts of the analysis were performed by the authors themselves. Descriptive statistics (median, mean, standard deviation, and independent student $t$-test) were calculated for continuous variables while frequencies/percentages and Chi-square test were used for categorical variables. $P<0.05$ was always considered significant.

Statistically significant variables in bivariate analysis were included in the multivariate logistic regression model developed for each of the study outcomes.

\section{RESULTS}

\section{Socio-Demographic Characteristics of the Study Population}

In this study, the questionnaire was introduced to 2,819 individuals, all of whom completed and returned the questionnaire electronically (Table 1). The mean (range) age of respondents was 29.47 (18-71) years. We divided the population into three groups according to age: young (18-35), middle (36-53), and elderly (>53). 73.9\% were young and only $4 \%$ of participants were elderly. More than two-thirds (72.6\%) of respondents were female and nearly half $(51.4 \%)$ were single. The majority live in the West Bank (83.5\%). Most of the participants (78.4\%) currently study in college or had graduated recently. Almost one-quarter (24.6\%) were smokers. Only $11.8 \%$ were health care workers and $45.5 \%$ admitted that they had a high-risk group living with them currently.

It was found that $1,144(40.6 \%), 1,261$ (44.7\%), and 1,283 (45.5\%) of respondents had low levels of staying home adherence, in-home precautions adherence, and quarantine understanding, respectively.

\section{Quarantine Characteristics of the Population}

As shown in Table 2 98\% of respondents believed that quarantine is important, and 2,173 (77.1\%) expressed fear of getting COVID19 or transmitting it to others. Only $14.9 \%$ of respondents 
TABLE 1 | Bivariate analysis of socio-demographic characteristics with dependent variables (Staying home adherence; In-home precautions adherence; Quarantine understanding; $P$-value presented was Chi-square significance; $N=2,819)$.

\begin{tabular}{|c|c|c|c|c|c|c|c|c|c|c|}
\hline \multirow{3}{*}{$\begin{array}{l}\text { Variables } \\
\text { Age }\end{array}$} & \multirow[t]{3}{*}{$N(\%)$} & \multicolumn{2}{|c|}{$\begin{array}{l}\text { Staying home } \\
\text { adherence }\end{array}$} & \multirow[t]{3}{*}{$P$-value } & \multicolumn{2}{|c|}{$\begin{array}{l}\text { In-home precautions } \\
\text { adherence }\end{array}$} & \multirow[t]{3}{*}{$P$-value } & \multicolumn{2}{|c|}{$\begin{array}{c}\text { Quarantine } \\
\text { understanding }\end{array}$} & \multirow[t]{3}{*}{$P$-value } \\
\hline & & Low level & High level & & Low level & High level & & Low level & High level & \\
\hline & & $n=1,144$ & $n=1,675$ & & $n=1,261$ & $n=1,558$ & & $n=1,283$ & $n=1,536$ & \\
\hline $18-35$ & 2,083(73.9) & 825(39.6) & 1,258(60.4) & 0.106 & $979(47)$ & $1,104(53)$ & $<0.001^{\star}$ & $897(43.1)$ & 1,186(56.9) & $<0.001^{*}$ \\
\hline $36-53$ & $624(22.1)$ & $276(44.2)$ & $348(55.8)$ & & 247(39.6) & $377(60.4)$ & & $329(52.7)$ & 295(47.3) & \\
\hline$>53$ & $112(4)$ & 43(38.4) & 69(61.6) & & 35(31.3) & $77(68.7)$ & & $57(50.9)$ & $55(49.1)$ & \\
\hline \multicolumn{11}{|l|}{ Sex } \\
\hline Male & 768(27.2) & 468(60.9) & $300(39.1)$ & $<0.001^{*}$ & $377(49.1)$ & 391(50.9) & $0.04^{*}$ & 409(53.3) & $359(46.7)$ & $<0.001^{*}$ \\
\hline Female & $2,051(72.8)$ & 676(33) & $1,375(67)$ & & $884(43.1)$ & $1,167(56.9)$ & & $874(42.6)$ & $1,177(57.4)$ & \\
\hline \multicolumn{11}{|l|}{ Social status } \\
\hline Single & $1,449(51.4)$ & 539(37.2) & $910(62.8)$ & $<0.001^{\star}$ & $669(46.2)$ & $780(53.8)$ & 0.114 & 593(40.9) & $856(59.1)$ & $<0.001^{*}$ \\
\hline Relationship & 1,370(48.6) & $605(44.2)$ & $765(55.8)$ & & $592(43.2)$ & $778(56.8)$ & & $690(50.4)$ & $680(49.6)$ & \\
\hline \multicolumn{11}{|l|}{ Residency } \\
\hline Village & $1,380(49)$ & $618(44.8)$ & $762(55.2)$ & $<0.001^{\star}$ & $631(45.7)$ & $749(54.3)$ & 0.113 & $657(47.6)$ & $723(52.4)$ & $0.01^{*}$ \\
\hline City & 1,292(45.8) & $463(35.8)$ & $829(64.2)$ & & $576(44.6)$ & $716(55.4)$ & & $550(42.6)$ & $742(57.4)$ & \\
\hline Camp & $147(5.2)$ & $63(42.9)$ & $84(57.1)$ & & $54(36.7)$ & 93(63.3) & & $76(51.7)$ & $71(48.3)$ & \\
\hline \multicolumn{11}{|l|}{ Geographic area } \\
\hline West bank & 2,354(83.5) & $969(41.6)$ & 1,385(58.4) & $0.03^{*}$ & $1,060(45)$ & $1,294(55)$ & 0.768 & $1,059(45)$ & $1,295(55)$ & $0.014^{\star}$ \\
\hline Gaza strip & 270(9.6) & $118(43.7)$ & 152(56.3) & & 116(43) & 154(57) & & 144(53.3) & $126(46.7)$ & \\
\hline Jerusalem & 195(6.9) & $57(29.2)$ & 138(71.8) & & 85(43.6) & $110(56.4)$ & & $80(41)$ & $115(59)$ & \\
\hline \multicolumn{11}{|l|}{ Educational level } \\
\hline Secondary or less & $326(11.6)$ & 166(50.9) & $160(49.1)$ & $<0.001^{\star}$ & $151(46.3)$ & $175(53.7)$ & 0.068 & 207(63.5) & $119(36.5)$ & $<0.001^{*}$ \\
\hline Collage & $2,211(78.4)$ & 865(39.1) & $1,346(60.9)$ & & 1,002(45.3) & $1,209(54.7)$ & & $964(43.6)$ & $1,247(56.4)$ & \\
\hline Master or doctorate & 282(10) & $113(40.1)$ & 169(59.9) & & 108(38.3) & $174(61.7)$ & & $112(39.7)$ & $170(60.3)$ & \\
\hline \multicolumn{11}{|l|}{ Health care worker } \\
\hline Yes & $332(11.8)$ & 131(39.5) & $201(60.5)$ & 0.657 & 139(41.9) & 193(58.1) & 0.264 & $141(42.5)$ & $191(57.5)$ & 0.236 \\
\hline No & 2,487(88.2) & $1,013(40.7)$ & $1,474(59.3)$ & & $1,122(45.1)$ & $1,365(54.9)$ & & $1,142(45.9)$ & $1,345(54.1)$ & \\
\hline \multicolumn{11}{|c|}{ Monthly income (Shekel) } \\
\hline$<2,000$ & $568(20.1)$ & $240(42.3)$ & $328(57.7)$ & 0.512 & $232(40.9)$ & 336(59.) & $0.032^{*}$ & 297(52.3) & $271(47.7)$ & $<0.001^{*}$ \\
\hline $2,000-5,000$ & $1,552(55.1)$ & $631(40.7)$ & $921(59.3)$ & & 692(44.6) & $860(55.4)$ & & $706(45.5)$ & $846(54.5)$ & \\
\hline$>5,000$ & 699(24.8) & 273(39.1) & 426(60.9) & & $337(48.2)$ & $362(51.8)$ & & $280(40.1)$ & 419(59.9) & \\
\hline \multicolumn{11}{|l|}{ Smoking/Shisha } \\
\hline Yes & 693(24.6) & $350(50.5)$ & $343(49.5)$ & $<0.001^{\star}$ & $328(47.3)$ & $365(52.7)$ & 0.113 & $363(52.4)$ & $330(47.6)$ & $<0.001^{*}$ \\
\hline No & $2,126(75.4)$ & $794(37.4)$ & 1,332(62.6) & & 933(43.9) & 1,193(56.1) & & $920(43.3)$ & $1,266(56.7)$ & \\
\hline \multicolumn{11}{|c|}{ High risk group in home } \\
\hline Yes & $1,283(45.5)$ & $539(42)$ & $744(58)$ & 0.158 & $536(41.8)$ & $747(58.2)$ & $0.004^{*}$ & $705(55)$ & $831(45)$ & 0.653 \\
\hline No & $1,536(54.5)$ & 605(39.4) & $931(60.6)$ & & $725(47.2)$ & $811(52.8)$ & & $578(37.6)$ & $705(62.4)$ & \\
\hline
\end{tabular}

${ }^{*} P$-value is statistically significant.

had jobs that required them to leave home during quarantine, and only $85(3 \%)$ had at least one of their relatives infected with COVID-19. The two most common sources of information about quarantine and precautions were social media and television/radio (59.5\% and $18.6 \%$, respectively). Nearly $80.2 \%$ admitted that they were properly informed about the quarantine, and $29.3 \%$ documented inadequate food supplies to withstand the quarantine period.

However, most people (38.2\%) used to spend between 6 and $10 \mathrm{~h}$ outside the home before the quarantine. Most respondents (94.1\%) correctly identified that quarantine aimed to protect society. Only $52.6 \%$ understood that quarantine restrictions aimed to protect members of their household. Nearly 59.4\% correctly reported that quarantine would not protect them.

\section{Bivariate Analysis of the Study Main Outcomes}

Staying home adherence outcome was found to have statistically significant associations with the following socio-demographic variables $[($ sex, social status, residency, geographic area, educational level, and smoking); $P<0.05$, Table 1] and the following quarantine characteristic variables [(quarantine type, fear of getting COVID-19 or transmitting it, being properly 
TABLE 2 | Bivariate analysis of quarantine characteristics with dependent variables (Staying home adherence; In-home precautions adherence; Quarantine understanding; $P$-value presented was Chi-square significance; $N=2,819$ ).

\begin{tabular}{|c|c|c|c|c|c|c|c|c|c|c|}
\hline \multirow[t]{2}{*}{ Variables } & \multirow[t]{2}{*}{$N(\%)$} & \multicolumn{2}{|c|}{$\begin{array}{l}\text { Staying home } \\
\text { adherence }\end{array}$} & \multirow[b]{2}{*}{$P$-value } & \multicolumn{2}{|c|}{$\begin{array}{l}\text { In-home precautions } \\
\text { adherence }\end{array}$} & \multirow[b]{2}{*}{$P$-value } & \multicolumn{2}{|c|}{$\begin{array}{c}\text { Quarantine } \\
\text { understanding }\end{array}$} & \multirow[b]{2}{*}{$P$-value } \\
\hline & & $\begin{array}{l}\text { Low level } \\
n=1,144\end{array}$ & $\begin{array}{l}\text { High level } \\
n=1,675\end{array}$ & & $\begin{array}{l}\text { Low level } \\
n=1,261\end{array}$ & $\begin{array}{l}\text { High level } \\
n=1,558\end{array}$ & & $\begin{array}{l}\text { Low level } \\
n=1,283\end{array}$ & $\begin{array}{l}\text { High level } \\
n=1,536\end{array}$ & \\
\hline \multicolumn{11}{|c|}{ Do you think quarantine is important? } \\
\hline Yes & $2,763(98)$ & $1,116(40.4)$ & $1,647(59.6)$ & 0.147 & $1,232(44.6)$ & $1,531(55.4)$ & 0.248 & $1,238(44.8)$ & $1,525(55.2)$ & $<0.001^{\star}$ \\
\hline No & $56(2)$ & $28(50)$ & $28(50)$ & & $29(51.8)$ & 27(48.2) & & 45(80.4) & 11(19.6) & \\
\hline \multicolumn{11}{|l|}{ Type of quarantine } \\
\hline Obliged to stay at home & 2,398(85.1) & 902(37.6) & $1,496(62.4)$ & $<0.001^{\star}$ & $1,046(43.6)$ & $1,334(56.4)$ & 0.356 & $1,060(44.2)$ & $1,338(55.8)$ & $0.001^{\star}$ \\
\hline I have to work outside home & $421(14.9)$ & $242(57.5)$ & $179(42.5)$ & & $197(46.8)$ & 224(35.2) & & 223(53) & 198(47) & \\
\hline \multicolumn{11}{|c|}{ Any of relatives or acquainted infected? } \\
\hline Yes & $85(3)$ & $34(40)$ & $51(60)$ & 0.912 & $40(47.1)$ & 45(52.9) & 0.661 & 39(45.9) & $46(54.1)$ & 0.945 \\
\hline No & $2,734(97)$ & $1,110(40.6)$ & $1,624(59.4)$ & & $1,221(44.7)$ & $1,513(55.3)$ & & $1,244(45.5)$ & $1,490(54.5)$ & \\
\hline \multicolumn{11}{|c|}{ Afraid of getting COVID-19 or transmit it? } \\
\hline Yes & $2,173(77.1)$ & $852(39.2)$ & $1,321(60.8)$ & $0.006^{\star}$ & $950(43.7)$ & $1,223(56.3)$ & $0.047^{\star}$ & $897(41.3)$ & $1,276(58.7)$ & $<0.001^{\star}$ \\
\hline No & $646(22.9)$ & 292(45.2) & $354(54.8)$ & & $311(48.1)$ & $335(51.9)$ & & $386(59.8)$ & $260(40.2)$ & \\
\hline \multicolumn{11}{|c|}{ Properly informed about quarantine } \\
\hline Yes & $2,262(80.2)$ & 884(39.1) & $1,378(60.9)$ & $0.001^{*}$ & $976(43.2)$ & $1,286(56.8)$ & $0.001^{*}$ & $984(43.5)$ & $1,278(56.5)$ & $<0.001^{*}$ \\
\hline No & $557(19.8)$ & $260(46.7)$ & 279(53.3) & & $285(51.2)$ & $272(48.8)$ & & 299(53.7) & 258(46.3) & \\
\hline \multicolumn{11}{|l|}{ Source of information } \\
\hline Television or radio & $525(18.6)$ & $219(41.7)$ & $306(58.3)$ & $0.027^{\star}$ & $221(42.1)$ & $304(57.9)$ & $<0.001^{*}$ & 259(49.3) & $266(50.7)$ & $<0.001^{*}$ \\
\hline Official government agencies & $359(12.7)$ & 134(37.3) & $225(62.7)$ & & $120(33.4)$ & 239(66.6) & & 132(36.8) & $227(63.2)$ & \\
\hline A health care worker & 159(5.6) & $67(42.1)$ & $92(57.9)$ & & $58(36.5)$ & $101(63.5)$ & & 63(39.6) & $96(60.4)$ & \\
\hline Social media & $1,676(59.5)$ & 669(39.9) & $1,007(60.1)$ & & $806(48.1)$ & $870(51.9)$ & & $770(45.9)$ & $906(54.1)$ & \\
\hline Conversation with other people & 100(3.6) & $55(55)$ & $45(45)$ & & $56(56)$ & $44(44)$ & & $59(59)$ & $41(41)$ & \\
\hline \multicolumn{11}{|c|}{ Enough food supply to withstand quarantine period? } \\
\hline Yes & $1,994(70.7)$ & $750(37.6)$ & $1,244(62.4)$ & $<0.001^{*}$ & $876(43.9)$ & $1,118(56.1)$ & 0.184 & $855(42.9)$ & $1,139(57.1)$ & $<0.001^{*}$ \\
\hline No & $825(29.3)$ & $394(47.8)$ & $431(52.2)$ & & $385(46.7)$ & $440(53.3)$ & & $428(51.9)$ & $397(48.1)$ & \\
\hline \multicolumn{11}{|l|}{ Quarantine duration } \\
\hline 1-2 weeks & $187(6.6)$ & $98(52.4)$ & $89(47.6)$ & $<0.001^{\star}$ & $86(46)$ & $101(54)$ & 0.103 & 102(54.5) & $85(45.5)$ & $0.023^{*}$ \\
\hline $2-3$ weeks & $847(30.1)$ & $355(41.9)$ & $847(58.1)$ & & $357(42.2)$ & $490(57.8)$ & & $396(46.8)$ & $847(53.2)$ & \\
\hline 3-4 weeks & $786(27.9)$ & $331(42.1)$ & $786(57.9)$ & & $378(48.1)$ & 408(51.9) & & $357(45.4)$ & $786(54.6)$ & \\
\hline$>4$ weeks & $999(35.4)$ & $360(36)$ & $639(67)$ & & $440(44)$ & $559(56)$ & & $428(42.8)$ & $571(57.2)$ & \\
\hline \multicolumn{11}{|c|}{ Average hours out home before quarantine } \\
\hline$<2 \mathrm{~h}$ & $584(20.7)$ & 206(35.3) & $378(64.7)$ & $<0.001^{*}$ & $261(44.7)$ & 323(55.3) & 0.851 & 289(49.5) & 295(50.5) & $0.020^{\star}$ \\
\hline $2-6 h$ & $776(27.5)$ & $337(43.4)$ & $439(56.6)$ & & $356(45.9)$ & $776(54.1)$ & & $344(44.3)$ & $432(55.7)$ & \\
\hline $6-10 h$ & 1,075(38.2) & 415(38.6) & $660(61.4)$ & & $478(44.5)$ & $1,075(55.5)$ & & $460(42.8)$ & $615(57.2)$ & \\
\hline$>10 h$ & 384(13.6) & 186(48.4) & 198(51.6) & & 166(43.2) & $384(56.8)$ & & $190(49.5)$ & 194(50.5) & \\
\hline
\end{tabular}

${ }^{*} P$-value is statistically significant.

informed about quarantine, source of information, having an adequate food supply, quarantine duration, and average hours outside the home before quarantine); $P<0.05$, Table 2].

Regarding in-home precautions adherence outcome, statistically significant associations were found with the following socio-demographics [(age, sex, monthly income, and high-risk group in the home); $P<0.05$, Table 1] and the following quarantine characteristics [(fear of getting COVID-19 or transmitting it, being properly informed about quarantine, and source of information); $P<0.05$, Table 2].

On the other side, quarantine understanding outcome was found to be significantly associated with these socio-demographics [(age, sex, social status, residency, geographic area, educational level, monthly income, and smoking); $P<0.05$, Table 1] and the following quarantine characteristic variables [(belief in the importance of quarantine, quarantine type, fear of getting COVID-19 or transmitting it, being properly informed about quarantine, source of information, having enough food supply, quarantine duration, and average hours outside the home before quarantine); $P<$ 0.05 , Table 2].

As shown in Figure 1, those with higher mean scores of the self-reported rating of adherence to quarantine were significantly more likely to have a high-level of staying home adherence compared to those who reported lower mean scores (mean \pm SD $=9.11 \pm 1.26$ and $7.56 \pm 2.15 ; P<0.001$; respectively). 


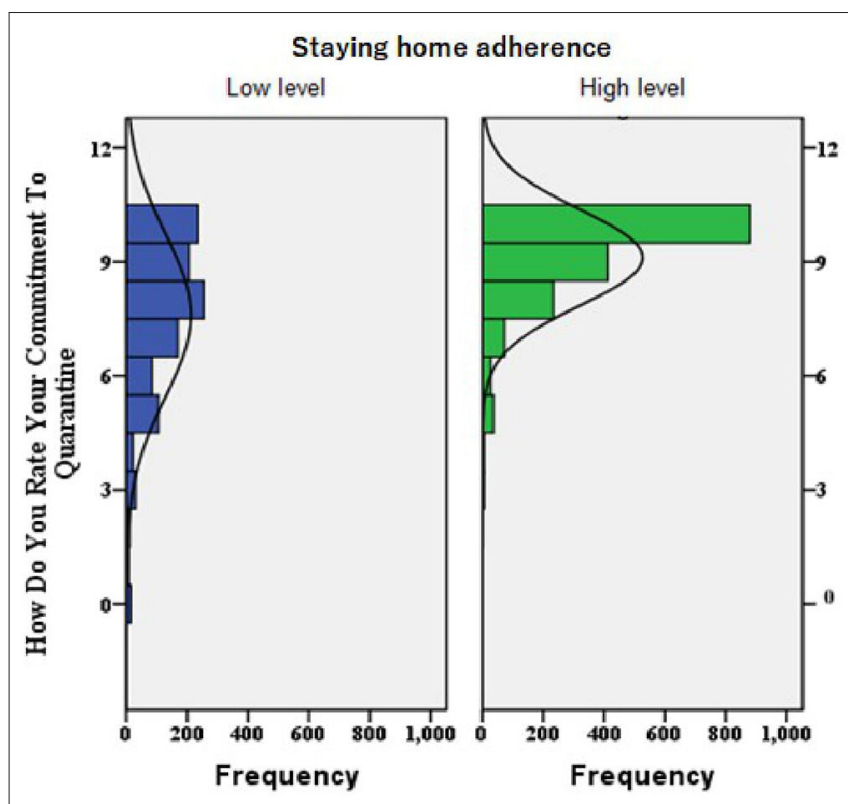

FIGURE 1 | A histogram chart built for the distribution of participants' self-rating of adherence to quarantine among the high and low levels of staying home adherence ( $P$-value of $t$-test analysis for the mean difference between the two groups was $<0.001$; i.e., High-level group showed significantly higher Mean \pm SD self-rating of adherence to quarantine compared to low-level, 9.11 \pm 1.26 and $7.56 \pm 2.15$, respectively).

\section{Multivariate Logistic Regression for Staying Home Adherence}

The multivariate logistic regression model for staying home adherence outcome predictors is shown in Table 3. As shown, female sex, city residents, and higher educational levels (master and doctorate) were associated with a higher level of staying home adherence [ORs (95\%CIs) = 2.72 (2.27-3.37); 1.37 (1.16-1.64); and 1.51 (1.06-2.16); respectively]. Furthermore, being informed through official government sources and having adequate food supply were more likely to result in a higher level of staying home adherence [ORs (95\%CIs) $=1.38$ (1.03$1.86)$ and 1.23 (1.03-1.47); respectively). Being obliged to stay at home was also a significant positive predictor of a higher level of staying home adherence. On the contrary, being in a relationship (engaged or married) was inversely related to staying home adherence $[\mathrm{OR}(95 \% \mathrm{CI})=0.7(0.59-0.83)]$. Other variables did not remain significant after adjusting for other variables in the model.

\section{Multivariate Logistic Regression for In-Home Precautions Adherence}

In-home precautions adherence model shown in Table 4; older age groups (36-53 and 54-71 years) showed strong positive associations with a higher level of in-home precautions adherence compared to younger adults $[\mathrm{OR}(95 \% \mathrm{CI})=1.37$ (1.14-1.66) and 2.17 (1.42-3.30); respectively].

Furthermore, female sex, having a high-risk group in the home, and considering official government agencies as a source of information were significantly associated with a higher level of in-home precautions adherence [OR $(95 \% \mathrm{CI})=1.35(1.14-$ 1.61), 1.23 (1.06-1.43), and 1.58 (1.19-2.10); respectively]. Being properly informed about quarantine was also a significant positive predictor. On the other hand, higher monthly income ( $>5,000$ Shekels) was inversely related to in-home precautions adherence [OR $(95 \% \mathrm{CI})=0.72(0.57-0.90)]$.

\section{Multivariate Logistic Regression for Quarantine Understanding}

The multivariate logistic regression model for quarantine understanding outcome predictors is shown in Table 5. Female sex, city residents, and a higher educational level (master and doctorate) were associated with a higher level of quarantine understanding [ORs (95\%CIs) $=1.29$ (1.06-1.58); 1.21 (1.021.44); and 2.29 (1.60-3.27); respectively]. Furthermore, being informed through official government sources, being properly informed, and fear of catching COVID-19 were significant predictors of a higher level of quarantine understanding [ORs $(95 \%$ CIs $)=1.64(1.23-2.20)$; 1.32 (1.08-1.62); and 2.03 (1.68$2.45)$; respectively]. Moreover, higher monthly income $(>5,000$ shekels), being obligated to stay at home, and those who believe that quarantine is important were associated with a higher level of quarantine understanding. On the contrary, being in a relationship (engaged or married) and smokers (cigarette or shisha) were inversely related to quarantine understanding [OR $(95 \% \mathrm{CI})=0.71(0.59-0.85)$ and 0.80 (0.66-0.97); respectively]. Other variables did not remain significant after adjusting for other variables in the model.

\section{DISCUSSION}

The present study aimed to assess staying home adherence, in-home precautions adherence, and quarantine understanding among Palestinian society during the COVID-19 pandemic lockdown.

Females, city residents, those with a higher level of education, those obliged to stay at home as a type of quarantine, and those considering official government agencies as a source of information were associated with a higher level of staying home adherence and quarantine understanding. This could be explained by the cultural background of Palestinian society where males usually spend more time working outside the home. In our study, $47 \%$ of females and $64.4 \%$ of males reported more than $6 \mathrm{~h}$ on average outside the home before the quarantine. Police forces are usually more distributed in city centers compared to villages, and cities are usually more crowded; therefore the risk of COVID-19 is higher. On one hand, higher educated-people understand the risk of transmission and infection more which could affect their understanding and adherence compared to lesseducated individuals. On the other hand, higher-educated people usually have jobs that can be performed from the home through online applications, whereas less-educated people usually have craft jobs that require them to leave the home. In a study in Israel during the same pandemic, it was noted that the compliance rate to self-isolation was affected by loss of income, as the compliance rate dropped from 94 to $57 \%$ when income was not compensated through the government (16). A study 
TABLE 3 | Multivariate logistic regression model for factors associated with staying home adherence $(N=2,819)$.

\begin{tabular}{|c|c|c|c|c|c|}
\hline Explanatory variable & Beta coefficient & Standard error & AOR! & $95 \% \mathrm{Cl}^{\sim}$ & $P$-value \\
\hline \multicolumn{6}{|l|}{ Sex } \\
\hline Female & 1.02 & 0.10 & 2.77 & $2.27-3.37$ & $<0.001$ \\
\hline \multicolumn{6}{|l|}{ Social status } \\
\hline Relationship & -0.36 & 0.09 & 0.70 & $0.59-0.83$ & $<0.001$ \\
\hline City & 0.32 & 0.09 & 1.37 & $1.16-1.64$ & $<0.001$ \\
\hline Camp & 0.27 & 0.19 & 1.31 & $0.90-1.92$ & 0.162 \\
\hline Village ${ }^{*}$ & - & - & - & - & - \\
\hline \multicolumn{6}{|l|}{ Geographic area } \\
\hline West bank & -0.34 & 0.17 & 0.71 & $0.51-1.0$ & 0.053 \\
\hline Master or doctorate & 0.41 & 0.18 & 1.51 & $1.06-2.16$ & 0.023 \\
\hline Secondary or less ${ }^{\star}$ & - & - & - & - & - \\
\hline \multicolumn{6}{|l|}{ Smoking/Shisha } \\
\hline Yes & -0.12 & 0.10 & 0.89 & $0.73-1.09$ & 0.246 \\
\hline $\mathrm{No}^{*}$ & - & - & - & - & - \\
\hline \multicolumn{6}{|l|}{ Type of quarantine } \\
\hline I am obliged to stay at home & 0.63 & 0.12 & 1.87 & $1.49-2.34$ & $<0.001$ \\
\hline My work requires that I stay outdoors* & - & - & - & - & - \\
\hline \multicolumn{6}{|c|}{ Afraid of getting COVID-19 or transmit it? } \\
\hline Yes & 0.18 & 0.10 & 1.2 & $0.99-1.45$ & 0.063 \\
\hline Social media & 0.09 & 0.11 & 1.09 & $0.89-1.35$ & 0.405 \\
\hline Conversations with other people & -0.31 & 0.24 & 0.74 & $0.46-1.17$ & 0.193 \\
\hline Television or radio* & - & - & - & - & - \\
\hline \multicolumn{6}{|c|}{ Enough food supply to withstand quarantine period } \\
\hline Yes & 0.21 & 0.09 & 1.23 & $1.03-1.47$ & 0.023 \\
\hline $\mathrm{No}^{*}$ & - & - & - & - & - \\
\hline \multicolumn{6}{|l|}{ Quarantine duration } \\
\hline 2-3 Weeks & 0.23 & 0.17 & 1.26 & $0.90-1.77$ & 0.186 \\
\hline 3-4 Weeks & 0.15 & 0.18 & 1.16 & $0.82-1.63$ & 0.407 \\
\hline$>4$ Weeks & 0.30 & 0.17 & 1.35 & $0.97-1.90$ & 0.080 \\
\hline $1-2$ Weeks* $^{*}$ & - & - & - & - & - \\
\hline \multicolumn{6}{|c|}{ Average hours out of home before quarantine } \\
\hline$<2 \mathrm{~h}$ & 0.27 & 0.15 & 1.32 & $0.99-1.76$ & 0.063 \\
\hline $2-6 h$ & -0.13 & 0.14 & 0.88 & $0.67-1.15$ & 0.338 \\
\hline $6-10 \mathrm{~h}$ & 0.11 & 0.13 & 1.11 & $0.86-1.44$ & 0.421 \\
\hline$>10 h^{*}$ & - & - & - & - & - \\
\hline
\end{tabular}

${ }^{*}$ Reference category. $\sim \mathrm{Cl}$, Confidence interval; !AOR, Adjusted odds ratio (AOR for high level as compared with low level). Enter method was used. 
TABLE 4 | Multivariate logistic regression model for factors associated with in-home precautions adherence $(N=2,819)$.

\begin{tabular}{|c|c|c|c|c|c|}
\hline Explanatory variable & Beta coefficient & Standard error & AOR! & $95 \% \mathrm{Cl}^{\sim}$ & $P$-value \\
\hline \multicolumn{6}{|l|}{ Sex } \\
\hline Female & 0.30 & 0.09 & 1.35 & $1.14-1.61$ & 0.001 \\
\hline Male $^{*}$ & - & - & - & - & - \\
\hline \multicolumn{6}{|l|}{ Age } \\
\hline $36-53$ & 0.32 & 0.10 & 1.37 & $1.14-1.66$ & 0.001 \\
\hline $54-71$ & 0.77 & 0.22 & 2.17 & $1.42-3.30$ & $<0.001$ \\
\hline $18-35^{\star}$ & - & - & - & - & - \\
\hline \multicolumn{6}{|l|}{ Monthly income (shekel) } \\
\hline $2,000-5,000$ & -0.19 & 0.10 & 0.83 & $0.68-1.01$ & 0.066 \\
\hline$>5,000$ & -0.33 & 0.12 & 0.72 & $0.57-0.90$ & 0.005 \\
\hline$<2,000^{\star}$ & - & - & - & - & - \\
\hline \multicolumn{6}{|l|}{ High risk group in home } \\
\hline Yes & 0.21 & 0.08 & 1.23 & $1.06-1.43$ & 0.008 \\
\hline $\mathrm{No}^{*}$ & - & - & - & - & - \\
\hline \multicolumn{6}{|c|}{ Afraid of getting COVID-19 or transmit it? } \\
\hline Yes & 0.14 & 0.09 & 1.15 & $0.96-1.38$ & 0.120 \\
\hline $\mathrm{No}^{*}$ & - & - & - & - & - \\
\hline \multicolumn{6}{|c|}{ Do you think that you have been properly informed about quarantine? } \\
\hline Yes & 0.21 & 0.10 & 1.23 & $1.01-1.49$ & 0.036 \\
\hline $\mathrm{No}^{*}$ & - & - & - & - & - \\
\hline \multicolumn{6}{|l|}{ Source of information } \\
\hline Official government agencies & 0.46 & 0.15 & 1.58 & $1.19-2.10$ & 0.002 \\
\hline A health care worker & 0.33 & 0.19 & 1.40 & $0.96-2.03$ & 0.080 \\
\hline Social media & -0.19 & 0.10 & 0.83 & $0.68-1.02$ & 0.070 \\
\hline Conversations with other people & -0.36 & 0.23 & 0.70 & $0.45-1.09$ & 0.113 \\
\hline Television or radio* & - & - & - & - & - \\
\hline
\end{tabular}

${ }^{\star}$ Reference category. $\sim \mathrm{Cl}$, Confidence interval; ! AOR, Adjusted odds ratio (AOR for high level as compared with low level). Enter method was used.

during the H1N1 pandemic quarantine in Victoria found that people who used official sources of information only compared to those who used both official and unofficial sources showed no differences in the odds of compliance (Odds Ratio 1.00, 95\% $\mathrm{CI}=0.69-1.44)$ (17). Official sources of information are usually trusted and considered as a clear source that people commit to and understand more clearly. However, in Australia, a study during the H1N1 pandemic found no differences in adherence rates between those who took the information from official vs. nonofficial sources (9), whereas in a Canadian study, the source of information was found to be significantly associated with quarantine understanding (18).

Having an adequate food supply in the home was associated with a higher level of staying home adherence. It is reasonable that those who secure their food resources before the quarantine can avoid leaving the home easily in contrast to others who will be worried about protect their family from starving. However, monthly income (>5,000 Shekels), fear of getting COVID19 or transmitting it, and being properly informed about quarantine were associated with a high-level of quarantine understanding. These again reinforce the importance of proper delivery of information to the public and the underlying fears from COVID-19 transmission and infection rate. An Australian study during the H1N1 pandemic reported that people who understand quarantine were more compliant with it compared to people who reported inadequacy of information (17). However, in the UK, a study during the COVID-19 pandemic (16) reported that functional fear rather than sociopolitical factors increased compliance rates, which highlights the effect of fear on public response. Those with higher monthly incomes might not have resisted the quarantine and they understood it more as they had enough currency and didn't worry about financial shortages. It is noteworthy that loss of income was found to be the most frequently cited problem in compliance with quarantine (19).

However, being in a relationship (engaged or married) was inversely related to a higher level of both staying home adherence and quarantine understanding. This may be in part due to more responsibilities toward household members to supply the home with what is needed during the quarantine. On the other side, anxiety and stress might play a role in this due to overstress between family members during the quarantine. Therefore, going out could be an opportunity to relax and to avoid more stress. Smoking (cigarette or Shisha) was inversely associated with quarantine understanding. Cigarette/Shisha smokers usually seek meeting friends more than nonsmokers. They are usually stressed and might not be able to handle and understand quarantine intentionally due to their carelessness and under-estimation of the risk. Moreover, the effect of financial status on their ability of smoking due to job loss may make them more stressed.

The elderly and those with a high-risk group living with them were more likely to have higher in-home precautions adherence. It is worth mentioning that the elderly are usually considered a high-risk group if infected with COVID-19, and 
TABLE 5 | Multivariate logistic regression model for factors associated with quarantine understanding $(N=2,819)$.

\begin{tabular}{|c|c|c|c|c|c|}
\hline Explanatory variable & Beta coefficient & Standard error & AOR! & $95 \% \mathrm{Cl}^{\sim}$ & $P$-value \\
\hline \multicolumn{6}{|l|}{ Sex } \\
\hline Female & 0.26 & 0.10 & 1.29 & $1.06-1.58$ & 0.012 \\
\hline \multicolumn{6}{|l|}{ Age } \\
\hline $36-53$ & -0.30 & 0.11 & 0.74 & $0.60-0.93$ & 0.008 \\
\hline \multicolumn{6}{|l|}{ Social status } \\
\hline Relationship & -0.35 & 0.10 & 0.71 & $0.59-0.85$ & $<0.001$ \\
\hline Single ${ }^{*}$ & - & - & - & - & - \\
\hline \multicolumn{6}{|l|}{ Residency } \\
\hline City & 0.19 & 0.09 & 1.21 & $1.02-1.44$ & 0.025 \\
\hline Gaza & -0.45 & 0.21 & 0.64 & $0.42-0.97$ & 0.035 \\
\hline Jerusalem* & - & - & - & - & - \\
\hline \multicolumn{6}{|l|}{ Educational level } \\
\hline Collage & 0.53 & 0.13 & 1.69 & $1.30-2.19$ & $<0.001$ \\
\hline Master or doctorate & 0.83 & 0.18 & 2.29 & $1.60-3.27$ & $<0.001$ \\
\hline Secondary or less ${ }^{\star}$ & - & - & - & - & - \\
\hline \multicolumn{6}{|l|}{ Monthly income (shekel) } \\
\hline $2,000-5,000$ & 0.16 & 0.11 & 1.17 & $0.95-1.45$ & 0.146 \\
\hline$>5,000$ & 0.27 & 0.13 & 1.31 & $1.01-1.69$ & 0.041 \\
\hline$<2,000^{\star}$ & - & - & - & - & - \\
\hline I am obliged to stay at home & 0.28 & 0.11 & 1.33 & $1.06-1.66$ & 0.012 \\
\hline My work requires that I stay outdoors* & - & - & - & - & - \\
\hline \multicolumn{6}{|c|}{ Afraid of getting COVID-19 or transmit it? } \\
\hline Yes & 0.71 & 0.10 & 2.03 & $1.68-2.45$ & $<0.001$ \\
\hline $\mathrm{No}^{*}$ & - & - & - & - & - \\
\hline \multicolumn{6}{|c|}{ Do you think that you have been properly informed about quarantine? } \\
\hline Yes & 0.28 & 0.10 & 1.32 & $1.08-1.62$ & 0.007 \\
\hline $\mathrm{No}^{*}$ & - & - & - & - & - \\
\hline \multicolumn{6}{|l|}{ Source of information } \\
\hline Official government agencies & 0.50 & 0.15 & 1.64 & $1.23-2.20$ & 0.001 \\
\hline A health care worker & 0.36 & 0.20 & 1.44 & $0.98-2.11$ & 0.061 \\
\hline Social media & 0.12 & 0.11 & 1.12 & $0.91-1.38$ & 0.276 \\
\hline Conversations with other people & -0.30 & 0.24 & 0.74 & $0.46-1.17$ & 0.200 \\
\hline Television or radio* & - & - & - & - & - \\
\hline \multicolumn{6}{|c|}{ Enough food supply to withstand quarantine period } \\
\hline Yes & 0.09 & 0.09 & 1.10 & $0.92-1.32$ & 0.309 \\
\hline $\mathrm{No}^{\star}$ & - & - & - & - & - \\
\hline
\end{tabular}


TABLE 5 | Continued

\begin{tabular}{|c|c|c|c|c|c|}
\hline Explanatory variable & Beta coefficient & Standard error & AOR! & $95 \% \mathrm{Cl}^{\sim}$ & $P$-value \\
\hline \multicolumn{6}{|l|}{ Quarantine duration } \\
\hline 2-3 Weeks & 0.19 & 0.17 & 1.20 & $0.86-1.68$ & 0.279 \\
\hline 3-4 Weeks & 0.20 & 0.17 & 1.22 & $0.87-1.71$ & 0.240 \\
\hline$>4$ Weeks & 0.23 & 0.17 & 1.26 & $0.91-1.76$ & 0.169 \\
\hline $1-2$ Weeks $^{*}$ & - & - & - & - & - \\
\hline \multicolumn{6}{|c|}{ Average hours out of home before quarantine } \\
\hline$<2 \mathrm{~h}$ & -0.04 & 0.14 & 0.96 & $0.73-1.28$ & 0.785 \\
\hline $2-6 h$ & 0.10 & 0.14 & 1.10 & $0.84-1.44$ & 0.488 \\
\hline 6-10h & 0.11 & 0.13 & 1.12 & $0.87-1.44$ & 0.378 \\
\hline$>10 h^{\star}$ & - & - & - & - & - \\
\hline
\end{tabular}

${ }^{\star}$ Reference category. $\sim \mathrm{Cl}$, Confidence interval; 'AOR, Adjusted odds ratio (AOR for high level as compared with low level). Enter method was used.

by the time of the study, the only two deaths from COVID-19 in Palestine were two elderly patients with co-morbidities (20). In-home precautions adherence might be considered crucial to protect those with a high-risk group in the home. Conversely, during a mumps outbreak at an American University, isolation compliance didn't significantly differ by gender, age, location of residence, or employment status (21). Surprisingly, high monthly income ( $>5,000$ Shekels) was inversely associated with in-home precautions adherence. This is in opposition to our expectations as those with a higher monthly income can usually afford to buy sanitizers and protective equipment. But it seems that the ability to buy differs from adherence. Their feelings of being able to be treated if infected might affect their adherence as they thought they have more currency for better affordable treatment. Furthermore, those people might have a higher nutritional status and were not afraid of COVID-19 infection and thought that they were strong enough not to catch the infection, mainly due to false information during COVID-19. A more likely explanation is that people with a monthly income of more than 5,000 Shekels have a healthier family, and are less likely to have a high-risk group in the home. In our study, $42.2 \%$ of people who had $>5,000$ Shekels as monthly income reported having a high-risk group in the home, while $57.8 \%$ of people with monthly income $<5,000$ Shekels reported having a high-risk group in the home.

It should be noted that only two factors (females and those who consider official government agencies as a source of information) were significantly associated with a higher level of the three study outcomes. Average hours spent outside of the home before quarantine and duration of quarantine did not affect any of the study outcomes. This is in accordance with other studies during the $\mathrm{H} 1 \mathrm{~N} 1$ pandemic in Australia (17). People might appreciate more factors and the severity of the disease and its transmission for adherence and quarantine understanding than the length of quarantine and the hours they usually spent outside of the home before the quarantine. Forcing the quarantine through the declaration of emergency bylaws might leave people to concentrate more on staying at home rather than the length of quarantine itself. As the study focused on factors affecting adherence to quarantine measures and one of the inclusion criteria was Palestinian individuals in Palestine under quarantine, the West Bank had the highest number of responders because both Gaza and
Jerusalem were not under lockdown until the last few days of the study.

This study could have some limitations. Selection bias could have occurred due to the sampling technique. Due to social distancing during quarantine, we disseminated the survey on social media, and this might in part exclude people who do not have access to the internet and social media, and also limit access to children and the elderly. Any participant who was younger than 18-years-old was excluded. Furthermore, only $4 \%$ of the participants were older than 53 years old. However, according to Index Mundi, only $8 \%$ of the Palestinian population were older than 55 years old, and around $36 \%$ of the population were younger than 15 years in 2020 (22), We believe that the elderly use the internet less frequently than other age groups, and for this reason, although the elderly group had been represented to some extent in our sample (4\%), our study could not represent all age groups. However, this was the only possible procedure to perform during the lockdown measures and it was useful in collecting the required information as fast and safely as possible. Systematic bias where over- or under-estimation of some measures due to self-reporting might also have been encountered. This study has several strengths, including a large sample size and the sampling timeframe that corresponded to the peak surge of COVID-19 cases in Palestine, which has had 613 cases and five deaths as per writing this paper (20). From an epidemiological point of view, our study might not represent the national level; however, taking into account the worldwide nature of the risk in this pandemic, we strongly believe that these data could provide useful information to be generalized to other countries and future pandemics.

\section{CONCLUSIONS}

It was seen that major effects depend mainly on the socioeconomic and financial status of the general population and the coordination between the major information resources (official government), social media, and the press. Hence, addressing such factors could enable the country to achieve higher adherence rates that can effectively decrease the spread of infection. It is important for policymakers to reach out to the community by every possible means during the lockdown to prevent the spread of false news, enhance their understanding, and update them 
with new measures. Policymakers' clear communication with the people is crucial for their reassurance, as such communication minimizes their fears of the unknown future. As financial status has a great role in the level of adherence, compensation of income loss and giving access to online jobs may decrease the burden of these lockdown measures on the population and ensure higher compliance.

\section{DATA AVAILABILITY STATEMENT}

The raw data supporting the conclusions of this article will be made available by the authors, without undue reservation.

\section{ETHICS STATEMENT}

The studies involving human participants were reviewed and approved by IRB of An-Najah National University. The ethics

\section{REFERENCES}

1. Bedford J, Enria D, Giesecke J, Heymann DL, Ihekweazu C, Kobinger G, et al. COVID-19: towards controlling of a pandemic. Lancet. (2020) 395:10158. doi: 10.1016/S0140-6736(20)30673-5

2. Wu Y-C, Chen C-S, Chan Y-J. The outbreak of COVID-19: an overview. J Chin Med Assoc. (2020). 83:217-20. doi: 10.1097/JCMA.0000000000000270

3. COVID-19 Emergency Situation Report 1 (as of 1200 Hrs, 24 March 2020): OCHA oPt in Collaboration With Humanitarian Partners. (2020). Available online at: https://www.ochaopt.org/content/covid-19-emergency-situationreport-1 (accessed March24, 2020).

4. Strong social distancing measures in the United States reduced the COVID-19 growth rate. Health Aff (Millwood). (2020) 39:1237-46. doi: 10.1377/hlthaff.2020.00608

5. Lu J, Gu J, Li K, Xu C, Su W, Lai Z, et al. COVID-19 outbreak associated with air conditioning in restaurant, Guangzhou, China, 2020. Emerg Infect Dis J. (2020) 26:1628. doi: 10.3201/eid2607.200764

6. Quarantine and Isolation: Centers for Disease Control and Prevention. (2017). Available online at: https://www.cdc.gov/quarantine/index.html (accessed September 29, 2017).

7. Nussbaumer-Streit B, Mayr V, Dobrescu AI, Chapman A, Persad E, Klerings I, et al. Quarantine alone or in combination with other public health measures to control COVID-19: a rapid review. Cochrane Database Syst Rev. (2020) 4:CD013574. doi: 10.1002/14651858.CD013574.pub2

8. Tognotti E. Lessons from the history of quarantine, from plague to influenza A. Emerg Infect Dis. (2013) 19:254-9. doi: 10.3201/eid1902. 120312

9. Webster RK, Brooks SK, Smith LE, Woodland L, Wessely S, Rubin GJ. How to improve adherence with quarantine: rapid review of the evidence. Public Health. (2020) 182:163-9. doi: 10.1016/j.puhe.2020.03.007

10. Jarvis CI, Van Zandvoort K, Gimma A, Prem K, Auzenbergs M, O'Reilly K, et al. Quantifying the impact of physical distance measures on the transmission of COVID-19 in the UK. BMC Med. (2020) 18:124. doi: 10.1186/s12916-020-01597-8

11. Kavanagh AM, Mason KE, Bentley RJ, Studdert DM, McVernon J, Fielding JE, et al. Leave entitlements, time off work and the household financial impacts of quarantine compliance during an H1N1 outbreak. BMC Infect Dis. (2012) 12:311. doi: 10.1186/1471-2334-12-311

12. Steens A, Freiesleben de Blasio B, Veneti L, Gimma A, Edmunds WJ, Van Zandvoort K, et al. Poor self-reported adherence to COVID-19-related quarantine/isolation requests, Norway, April to July 2020. Euro Surveill. (2020) 25:2001607. doi: 10.2807/1560-7917.ES.2020.25.37.2001607

13. Balsamo M, Carlucci L. Demographic and attitudinal factors of adherence to quarantine guidelines during COVID-19: the Italian model. SSRN Electron J. (2020) 11:559288. doi: 10.3389/fpsyg.2020.559288 committee waived the requirement of written informed consent for participation.

\section{AUTHOR CONTRIBUTIONS}

HA, NY, TA, and MH-Y designed study protocol and drafting the manuscript. HA coordinated the study protocol and conducted the statistical analysis. NY, TA, and MH-Y collected the data. All authors read and approved the final manuscript.

\section{ACKNOWLEDGMENTS}

We are grateful to all participants in this study for the time they devoted and their understanding.

14. Blendon RJ, Benson JM, DesRoches CM, Raleigh E, Taylor-Clark K. The public's response to severe acute respiratory syndrome in Toronto and the United States. Clin Infect Dis. (2004) 38:925-31. doi: 10.1086/382355

15. Reynolds DL, Garay JR, Deamond SL, Moran MK, Gold W, Styra R. Understanding, compliance and psychological impact of the SARS quarantine experience. Epidemiol Infect. (2008) 136:997-1007. doi: 10.1017/S0950268807009156

16. Harper CA, Satchell LP, Fido D, Latzman RD. Functional fear predicts public health compliance in the COVID-19 pandemic. Int J Ment Health Addict. (2020) 1-14. doi: 10.1007/s11469-020-00281-5

17. Kavanagh AM, Bentley RJ, Mason KE, McVernon J, Petrony S, Fielding $J$, et al. Sources, perceived usefulness and understanding of information disseminated to families who entered home quarantine during the H1N1 pandemic in Victoria, Australia: a cross-sectional study. BMC Infect Dis. (2011) 11:2. doi: 10.1186/1471-2334-11-2

18. Hawryluck L, Gold WL, Robinson S, Pogorski S, Galea S, Styra R. SARS control and psychological effects of quarantine, Toronto, Canada. Emerg Infect Dis. (2004) 10:1206-12. doi: 10.3201/eid1007.030703

19. Rothstein MA, Talbott MK. Encouraging compliance with quarantine: a proposal to provide job security and income replacement. Am J Public Health. (2007) 97(Suppl 1):S49-S56. doi: 10.2105/AJPH.2006.097303

20. الفلسطينية و ا. فاير و س كور وونا في فلسطين. COVID-19. (2020). Available online at: https://www.corona.ps/ (accessed February 4, 2021).

21. Soud FA, Cortese MM, Curns AT, Edelson PJ, Bitsko RH, Jordan $\mathrm{HT}$, et al. Isolation compliance among university students during a mumps outbreak, Kansas (2006). Epidemiol Infect. (2009) 137:30-7. doi: 10.1017/S0950268808000629

22. West Bank Age structure (2020). Available online at: https://www. indexmundi.com/west_bank/age_structure.html (accessed November 27, 2020).

Conflict of Interest: The authors declare that the research was conducted in the absence of any commercial or financial relationships that could be construed as a potential conflict of interest.

The reviewer MA declared a shared affiliation with the authors to the handling editor at time of review.

Copyright (C) 2021 Al Zabadi, Yaseen, Alhroub and Haj-Yahya. This is an open-access article distributed under the terms of the Creative Commons Attribution License (CC $B Y)$. The use, distribution or reproduction in other forums is permitted, provided the original author(s) and the copyright owner(s) are credited and that the original publication in this journal is cited, in accordance with accepted academic practice. No use, distribution or reproduction is permitted which does not comply with these terms. 